\title{
Esa matriz llamada tango Entrevista a Diego Schissi
}

\author{
That Matrix Called Tango \\ Dialogue with Diego Schissi
}

\author{
Manuel González \\ manuelgonzalezponisio@gmail.com \\ Instituto de Investigación en \\ Producción y Enseñanza del Arte \\ Argentino y Latinoamericano. \\ Facultad de Bellas Artes. Universidad \\ Nacional de La Plata. Argentina \\ Recibido: 28/9/2018 \\ Aceptado: 15/2/2019
}

\begin{abstract}
Resumen
La entrevista que presentamos recorre los procesos a través de los cuales Diego Schissi trabaja en sus composiciones musicales con los materiales sonoros, en diálogo con el género tango. El pianista y compositor argentino forma parte de una nueva generación de artistas que dio un aire fresco a las músicas urbanas rioplatenses, desplazándose de los lugares comunes del tango, en lo que podría vincularse al modernismo piazzolliano, pero con un sello propio y novedoso.
\end{abstract}

\section{Palabras clave}

Tango; género musical; música popular; composición; Diego Schissi

\section{Abstract}

The interview presented shows the way that Diego Schissi works with sound materials on his musical compositions, in dialogue with the tango genre. The Argentine pianist and composer is part of a new generation of artists that gave a fresh air to urban music of Buenos Aires. Moving away from the tango cliches, he could be linked to Piazzollian modernism, but with its own and novel stamp.

\section{Keywords}

Tango; Music genre; Composition; Popular music; Diego Schissi 
Diego Schissi en un pianista y compositor argentino nacido en Buenos Aires en 1969. En los últimos años se ha convertido en un referente de las músicas populares rioplatenses y se ha movido del jazz al tango, de lo simple a lo complejo, de las vanguardias a lo popular. Fructífero compositor que va construyendo un camino propio, atento a los trabajos de sus colegas con quienes intercambia ideas y grabaciones. Recibe la distinción Konex de Platino, Grupo de Jazz en 2005 y en 2008 dos nominaciones para el Premio Clarín: Figura de Jazz y Revelación de Tango, lo cual describe su viraje y eclecticismo.

Formado en el Conservatorio Nacional Carlos López Buchardo y luego en la Universidad de Miami, reside en Estados Unidos entre 1989 y 1996, donde se desempeña como músico profesional y toca con artistas de la talla de Tito Puente, Néstor Torres, Maria Schneider, Joe Henderson, entre otros. De regreso a la Argentina, forma parte del Quinteto Urbano, grupo de jazz que adquiere notoriedad en la escena porteña. En el año 2000, y a partir de un interés por encontrar una identidad musical ligada al tango, ingresa a la Orquesta Escuela de Tango Emilio Balcarce. En 2008 edita Tren, su primer disco como solista y desde 2009 dirige el Diego Schissi Quinteto, donde comienza a incursionar definitivamente en el género tango. La instrumentación de piano, violín, bandoneón, guitarra y contrabajo es un factor decisivo para el compositor que utiliza lo tímbrico como un rasgo tanguero, pero, también, condensa materiales vinculados al jazz y a estéticas contemporáneas. Con esta formación realiza numerosas presentaciones nacionales e internacionales y edita cinco discos: Tongos (2010); Tipas y Tipos (2012); Hermanos (2014); Timba (2016) y Tanguera (2018).

Si uno tuviera que presentarte lo haría como músico de tango. Sin embargo, no hay en tu carrera un apego al género, al menos de manera univoca. ¿Lo sentís así? ¿Cómo es tu relación con el género?

$>$ Creo que ser músico de tango es, en mi caso, una construcción de muchos años. Por un lado hay un deseo muy grande de formar parte de esa familia musical, con todo lo que connota. No solamente la música en sí misma, sino la cuestión cultural, de pertenencia, casi te diría familiar, detrás del tango. Pero a la vez, siempre sentí una gran lejanía, una extranjería, y tuve que llegar de una manera indirecta, rebotando con otras situaciones musicales. Al final lo terminé sintiendo como una construcción consciente, como un fenómeno que tiene que ver más con una decisión que con la inevitabilidad que tiene, por ejemplo, un músico de folclore, que está asociado a lo que escuchó toda la vida, a lo que aprendió 
1 Aquí se refiere al Diego Schissi Quintet, con el cual toca desde 2009 . de una manera intuitiva. Yo, lo que aprendí intuitivamente es a tocar temas de Charly (García) y de Spinetta. Después hice un gran esfuerzo por vincularme al jazz, para luego hacer un gran esfuerzo por despegarme del jazz y empecé a sentir todas estas afinidades que te contaba primero con el tango y, atravesándolo todo, un deseo por escribir música. Entonces tiene algo de artificioso, si se quiere, el hecho de que lo que hacemos con el Quinteto ${ }^{1}$ sea tango. Pero creo que es una artificialidad que se apoya en un deseo sí genuino, sí honesto y sí verdadero, que es escribir música que tenga que ver con esa matriz que es el tango.

¿Podría decirse que pensás la música desde los materiales más que desde los géneros? ¿Es eso lo que ha ocurrido, por ejemplo, con los tongos? ¿Cómo son tus procesos de composición?

> Sí, creo que los géneros tienen la fuerza de darte un lugar de referencia, un punto de partida, un material, un espacio al que podés ir muy fácilmente, que te da mucha potencia musical. A la vez, paradójicamente, el deseo de componer música (lo digo de la forma más llana, ser compositor siempre tiende a sonar grandilocuente) casi por definición se lleva mal con los géneros, o podría. En mi caso se da un poco así, el género funciona más como un campo de tensión para lo compositivo que como un lugar plácido. Entonces, como mencionabas en la pregunta, tongos en vez de tangos, porque nunca terminan de ser tangos. Y en relación con los procesos de composición creo que se trata de tensar los materiales que uno encuentra por deseo compositivo y los materiales que propone un género, en este caso, el tango. Creo que esos dos puntos de partida generan un método de trabajo en sí mismo: cómo encontrar las intersecciones entre los materiales, cómo hacerlos entrar en tensión y, en definitiva, hacer pasar todo por un filtro estético en el que te sientas identificado, que sientas que tiene que ver con algo de lo que te gusta escuchar.

En tu obra seguís la tradición tanguera, salganeana podríamos decir, de escribir la totalidad de las notas que ocurren. ¿Qué cosas no escribís? Sea esto deliberado o no. Me refiero a materiales musicales concretos.

> Vos estás señalando un campo de tensión, no solo del tango, sino de cualquier música popular escrita, donde muchas veces uno se pregunta ¿para qué escribir todo? o ¿para qué escribir si es algo a lo que se puede llegar de manera intuitiva? Mis primeros proyectos compositivos tendían a ser, desde mi perspectiva 
actual, un poco sobrescritos, especialmente en la articulación y en los matices. Lo que aprendí a través de mi experiencia es que hay cosas que es mejor que no estén escritas. Está bien definir las alturas, los ritmos, las formas, los matices generales y alguna articulación también. Pero una escritura ultradetallada conspira con la frescura de la interpretación. Pero esto encuentra límites hacia los dos lados, cuando la escritura compositiva no está lo suficientemente definida también peca de falta de información. Si ponemos el paradigma de un grupo de jazz que usa una guía donde hay acordes y melodía, nada más, compositivamente quizás sirva. Pero para otros géneros, como el tango, deja demasiados parámetros librados a la espontaneidad de los intérpretes y excesivos acuerdos que no se pueden llevar a cabo espontáneamente. Por eso creo que hay un grado de información que debería estar en una partitura, quizás un setenta u ochenta por ciento, o al menos a eso apunto en mis composiciones. $Y$ después en el otro veinte o treinta por ciento hay cosas que son negociables, inclusive notas, inclusive cambios en la forma, inclusive matices: un matiz que pensaste que iba a ir de piano a forte puede llegar a ir de forte a piano, porque surge de estar tocando. Es un campo de tensión muy rico y para todos los que escribimos música es importante tenerlo en cuenta. Y también es una lección de humildad bastante grande: muchos temas ganan su verdadera dimensión, no solamente porque se convierten en sonido, sino porque lo interpretativo los pone en el justo lugar, mucho más allá de lo que uno definió en la escritura.

En una charla que diste en el Auditorio de la Facultad de Bellas Artes de la Universidad Nacional de La Plata llevaste algunas músicas para compartir con la audiencia. Allí invitaste a los participantes a evitar ver la partitura antes de la música o con la música. ¿Qué se roba la partitura?

$>$ En una época me parecía que lo más importante para hacer con una música que a uno le gustara era mirar la partitura todo el tiempo. Y después me di cuenta de que hay algo allí que te hace anticipar algunas cosas, que te distrae de otras, que te genera la ilusión de que vas a escuchar algo. Que le quita algo de sorpresa y algo de la concentración que necesita una escucha. Yo creo que la música se escucha sin partitura para tener una vivencia musical. Y creo que, justamente, se puede tomar muchísima información en el momento en que, habiendo captado con profundidad y concentración solo desde la audición, se observa cómo está escrito. Es un impacto mucho más fuerte y mucho más rico que entrometer la escritura desde el vamos. Eso no quita que después vengan 
sucesivas y múltiples escuchas de una música con la partitura, se aprende muchísimo también. Pero me parece que en algún punto del camino la partitura sobra y simplemente hay que escuchar.

Cuando le presentás tus composiciones a tus colegas ¿solés acompañarlo de grabaciones? ¿Considerás importante que tengan una escucha previa? ¿Tocás las músicas en el piano antes de comenzar a abordarlas en grupo? ¿Sacan algo de oído quienes te acompañan más allá de tener partes?

> Tengo la gran suerte de trabajar hace diez años con las mismas personas. En algún momento sí, acompañaba con grabaciones, pero ahora no forma parte de lo que hacemos, más allá de que todos leen muy bien y demás. Sí siento que es importante para determinadas situaciones partir de la audición, sobre todo si son novedosas. Pero la verdad creo que depende del caso, más allá de la idea que se quiera manejar. Hay determinadas dinámicas que funcionan en los grupos: cuando la gente lee bien en un grupo tiene la tendencia a ir por ese camino, más que sacarlo de oído, que me parece que es una práctica muy saludable, pero eso ya tiene que ver con determinados hábitos. Lo que sí me parece rico, y eso alguna vez lo hemos hecho sobre todo con materiales que son nuevos, es apartar las partituras y hacer un trabajo desde el oído, otra vez, para tener una captación que no esté mediada por la escritura. Necesitamos hacerlo, sobre todo con los materiales nuevos, materiales a los que no habíamos accedido.

Históricamente tuve un proceso en el que la escritura no formaba parte de la composición, en otro momento cuando escribía la música y la estudiaba como si fuera escrita por otro, y ahora estoy en un plano más integrado, en el que puedo tocar lo que escribo mientras lo estoy trabajando y, quizás, puedo tener una idea incompleta, porque las cosas que son para grupos en un piano siempre se tienen que reducir, pero puedo sentir cómo va a ser esa música y también me parece que es algo importante. Todo ese recorrido por fuera del piano también tuvo su importancia, creo que son todos estadios que pueden ser sucesivos. Hay metodologías que a cada uno le resultan cómodas y otras que van cambiando, dándole un perfil distinto a nuestro trabajo. Pero no podría recomendar una cosa por sobre otra. Por supuesto, si tenés la suerte de sentirte cómodo leyendo, cómodo tocando algo y todo te resulta fácil, entonces abordás todo. Pero cuando algo no viene tan fácil, vas aprendiendo durante los años: primero la escritura, después volvés al piano, después de oído, después con la lectura, y así. 
¿Cómo nació el disco homenaje a Mariano Mores? ¿Qué te dejó esa experiencia?

> El disco homenaje a Mores surgió por una invitación que tuvo el Quinteto. Me gustó cómo quedó el material, me parece que nos enfrentó a una de las primeras premisas relacionadas con un grupo de tango que es enfrentarse con el repertorio y el género. Más allá de que no hicimos versiones fieles a las originales, nos hizo reencontrar con escuchas de las versiones originales, con el impacto emotivo que tiene esa música, ya sea desde la letra, desde los materiales melódicos o armónicos. Fue una experiencia muy rica que tuvimos la suerte de repetir al año siguiente con un trabajo sobre la música de Astor Piazzolla. Creo que la experiencia de haber trabajado con Mores nos ayudó, aunque claro, la obra de Piazzolla tiene el plus de tener una mirada compositiva mucho más potente. Muchos parámetros están considerados en Piazzolla, mientras que en el homenaje a Mores hicimos un trabajo sobre todo en el campo melódico, tomándolo como punto de referencia; a veces ni siquiera sostuvimos las armonías originales, pero con Piazzolla fuimos mucho más cautos. Por lo tanto, el riesgo que implica trabajar con la obra de otros autores, donde tenés que decidir qué materiales tomás y cuáles sumás para dejar una posible marca propia terminó siendo provechoso y creo que alguna vez reincidiremos. 